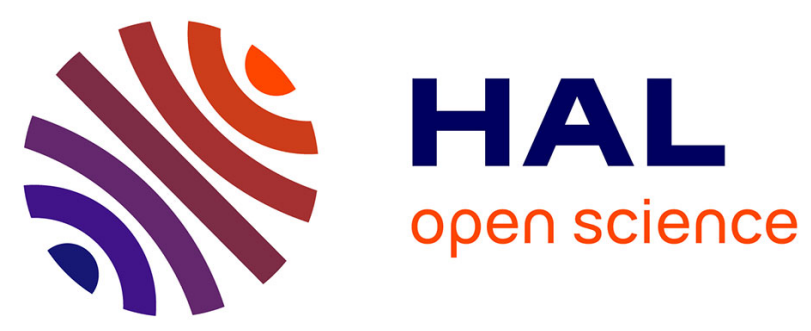

\title{
Connections and Disconnections in the Late Prehistory and Protohistory of the Levant: Discussion and perspectives
}

Fanny Bocquentin, Miquel Molist, Ianir Milevski

\section{- To cite this version:}

Fanny Bocquentin, Miquel Molist, Ianir Milevski. Connections and Disconnections in the Late Prehistory and Protohistory of the Levant: Discussion and perspectives. Paléorient, 2016, 42 (2), pp.203-208. hal-01996438

\section{HAL Id: hal-01996438 \\ https://hal.parisnanterre.fr/hal-01996438}

Submitted on 28 Jan 2019

HAL is a multi-disciplinary open access archive for the deposit and dissemination of scientific research documents, whether they are published or not. The documents may come from teaching and research institutions in France or abroad, or from public or private research centers.
L'archive ouverte pluridisciplinaire HAL, est destinée au dépôt et à la diffusion de documents scientifiques de niveau recherche, publiés ou non, émanant des établissements d'enseignement et de recherche français ou étrangers, des laboratoires publics ou privés.

\section{(1)(1) $\$(0)$}

Distributed under a Creative Commons Attribution - NonCommercial - ShareAlikel 4.0 


\title{
CONNECTIONS AND DISCONNECTIONS IN THE LATE PREHISTORY AND PROTOHISTORY OF THE LEVANT: DISCUSSION AND PERSPECTIVES
}

\author{
F. BOCQUENTIN, M. MOLIST and I. MILEVSKI
}

In the present thematic volume of Paléorient we have addressed some facets of the socio-cultural connections and disconnections in the Levant during late Prehistory and Protohistory. The articles presented here deal with case studies across different areas of the Levant and at different periods showing similarities and/or dissimilarities. They offer new data and perspectives of research, which will be summarized and discussed in the following lines.

\section{CONNECTIONS AND DISCONNECTIONS OVER TIME AND TOPICS}

\section{PRE-POTTERY NEOLITHIC PERIOD}

This volume took on a fresh look at one of the most tangible evidence of inter-connections between the Northern and Southern Levant, which lasted several millennia, namely the obsidian exchange networks. J.J. Ibáñez and colleagues test and propose a critical review of the reciprocity model of K. Polanyi (1957) and the down-the-line trade model of C. Renfrew (1975) which implies simple exchanges from neighbours to neighbours where either all sites played the same role in the ensemble or either central sites would supply several other following a more complex settlement hierarchy (directional model). This model implies a decline of the proportion of obsidian in the lithic assemblages going towards the south. Discrepancies with the archaeological data were noted suggesting more complex trade as does ethnographic observations. Those latter ones show that, in numerous cases, distant partners play an important role in trades, which outnumbered interactions with closer neighbours. Following these ethnographic examples, the authors intend mathematical simulations of complex network model, which better fit the archaeological data. They propose the existence of 'expedition' or 'visiting trade' of a small part of the group to distant communities at several occasions of the year that would also explain why the reduction technique of obsidian is very specific and homogeneous across the Levant. The authors consider this network as inherited from the settlement process, which requires communities to build new forms of interrelations.

We examine as well a trans-chronocultural and pan-regional phenomenon namely the practice of skull removal. In order to avoid comparative bias, F. Bocquentin et al. focus on removal operated in clear primary context (single or multiple graves) and show the evolution of this treatment across the Natufian and PPNA-PPNB. ${ }^{1}$ Skull/cranium removal starts to be an anticipated step of the funerary treatment at the Late Natufian. With time this custom shows a continuous amplification in the Southern Levant followed by a drastic decline at the beginning of the $7^{\text {th }}$ millennium. In the Northern Levant while this custom met with some success during the PPNA and the EPPNB, a clear decrease is attested from the MPPNB. This disruption is a potential piece of evidence of a withdrawal of south-north burial customs interaction. Moreover, after a review of the literature, the authors point towards several operational chains in

1. Abbreviations utilized here: PPNA=Pre-Pottery Neolithic A, PPNB=PrePottery Neolithic B, PPNC=Pre-Pottery Neolithic C, EPPNB=Early PPNB, MPPNB=Middle PPNB, LPPNB=Late PPNB, FPPNB=Final PPNB, PN=Pottery Neolithic; EPN=Early Pottery Neolithic; LPN=Late Pottery Neolitihic; EC=Early Chalcolithic, LC=Late Chalcolithic; EBA=Early Bronze Age; MBA=Middle Bronze Age. 
skull removal and recall the fact that apparent similarities might be the results of very different processes.

Recent excavations and new ${ }^{14} \mathrm{C}$ dates gathered since the last decade give the opportunity to P. Edwards to update and refine the discussion on the chronology and dispersal of the PPNB (e.g., Edwards and Sayej 2007). Through a comprehensive summary of the data available across the Levant and Cyprus the author highlights an origin in the Euphrates region with a rapid spread towards the south through a series of pulses: first, towards the Levantine corridor and Cyprus from 8600 cal. BC, later in Jordan and finally easterly to the arid areas. The author supports a coeval diffusion of several cultural elements of EPPNB (such as rectilinear architecture, double tanged projectile points or bidirectional blade technology), which will be soon adopted and integrated to autochthonous traditions. He promotes a distinctive nomenclature in order to take into consideration these new cultural entities generated in each geographical area.

The paper presented by F. Borrell and H. Khalaily focuses on the evolution of bidirectional blade technology, one of the major cultural components of the shared PPNB entities in the Levant and Mesopotamia. The lithic assemblages of several sites of the Levant located in different ecosystems serve as a basis for discussing the evolutionary process, from which results the abandonment of bidirectional technology at the eve of the PN. Whatever was the local variant of this complex chaîne opératoire over the regions, whatever were the socioeconomic contexts of the sites being part of the corpus, the same simplification in the production of chipped flint tools is observed as well as the same following predominance of flake and unidirectional blade productions. However the chronology of this decline is different and the causes might also have varied. The authors convincingly show that the phenomenon started earlier than previously assumed in the Middle Euphrates Valley during the LPPNB. By contrast, they clearly demonstrate the predominance of bidirectional technology until the mid- $7^{\text {th }}$ millennium in the Southern Levant (FPPNB/PPNC) while its presence beyond the LPPNB was highly debated. In the Syrian central steppe, bidirectional technology lasted at least through the first half of the $7^{\text {th }}$ millennium (FPPNB), later sites and the introduction of the pottery remaining undocumented in this area. Altogether they have brought to our attention that the abandonment of bidirectional technology always predates the adoption of pottery.

\section{POTTERY NEOLITHIC/EARLY CHALCOLITHIC}

By touching the ceramic phases of the Neolithic cultures and searching for similarities and differences between the Northern and Southern Levant in the $7^{\text {th }}-5^{\text {th }}$ millennia BC, the question of how contemporary are the new defined cultures (Yarmukian, Halafian, Wadi Rabah, Ubaid) has been treated.

The EPN is the focus of the article presented by J. Vieugué and colleagues, where pottery function and diet habits from the Southern Levant are described and compared to available northern Levantine data. This is a pioneering multidisciplinary functional approach which combines typometric and use wear analyses. The authors propose four groups of ceramic vessels: large storage containers, jars, cooking pots, containers suitable for food serving and consumption. Taking into account their long lifespan, storage vessels largely dominated the Yarmukian assemblages. Cooking pots show a certain degree of standardization in terms of forms and uses. Preliminary comparisons with northern contemporary ceramic containers show some interesting discrepancies in terms of proportion of vessel categories. In the Northern Levant liquid storage and cooking pots are more numerous while long-term storage containers are fewer. Yet no substantial differences between northern and southern Levantine faunal assemblages are noted; and botanical remains are too limited to be taken into consideration. Further investigations are needed for discussing potential reasons for the divergences observed in ceramic functional categories.

More issues dealing with the LPN/ECh cultures of the $6^{\text {th }}$ $5^{\text {th }}$ millennia BC are presented. A. Gómez Bach and colleagues, and I. Milevski and colleagues review the available data in order to discuss connections between Northern Halaf cultures and the southern Wadi Rabah cultures and vice versa. In spite of the fact that there is a need for establishing a consolidated chronological framework for these $6^{\text {th }}-5^{\text {th }}$ millennia BC groups both in the North and the South, these authors defend the fact that several fruitful comparisons can be done showing more connections than in the past. Various elements of comparison are selected by Gómez Bach et al. who show some synchronous developments to search for-e.g., beyond typological classifications on functional utilizations of ceramic items or in settlement organization. Despite a certain gap in the data of the Central Levant, interaction networks during the $6^{\text {th }}$ millennium appear consolidated. I. Milevski and colleagues show that the distribution of several items permits to firmly locate the boundary between these ceramic entities in the Hulah basin, often considered being at the northern limit of the Southern Levant. Comparing several iconographic objects discovered on both sides, the authors developed the idea of a possible line of influence from South to 
North. Indeed similar and coeval composite female figurines are found in several sites of the Southern Levant and the Hulah Valley. Moreover, the identical iconographic composition is found in Mesopotamia on two major sites, which post-date the southern sites. Other iconographic parallels show as well diffusion from north to south direction, revealing a significant interaction sphere (after Caldwell 1964) between distinct societies sharing symbolic values for a long time.

The concept of interaction spheres is examined and developed as well by E. Gabrieli who examines the connections of the Pre-Ghassulian entities of the Jordan Valley and nearby areas with the Halaf-Ubaid entities in the Northern Levant. ${ }^{2}$ Pottery decoration is here the main issue in order to found connected or disconnected phenomena in the archaeological record of the $5^{\text {th }}$ millennium $\mathrm{BC}$ sites. Contacts between the Levantine EC are explored going behind middle-range distances, including other areas of the Near East. A north to south direction transfer of technologies for the restricted manufacture of high quality ceramic vessels within a discontinuous chain of interaction is proposed.

\section{THE BRONZE AGE PERIOD}

We skip over the first urbanization in the Levant for a comparative study on the MBA tombs presented by P. Andreou. Political frontiers are well defined during the MBA and southern Levantine communities are far in their development from the more advanced northern contemporary urban states. However, tombs and funerary items do support some cultural and symbolic porosity. A stimulating development is made on tomb classification taking into account not only the typology of the architectural elements, but rather the spatial inner organization of the tomb as well as its place in the landscape. Doing so, the author refocuses attention on the utilization of the structure over time and its symbolic meaning together, or beyond, its primary funerary function. Previous typological conventions support the idea of a great disparity amongst the tombs from North to South and from coastal and inland areas. However, the author demonstrates that, even though differently built, some categories display the same spatial concept suggesting possible shared ritual behaviours. A comparable functional investigation of the vessels commonly found in MBA tombs, on the contrary, highlights a clear north-south border while scarabs and cylinder seals materialize a littoral-inland limit.

2. The LC does not appear in this issue (Akkermans and Schwartz 2009: 154180; Lovell and Rowan 2011).

\section{FORCES AND MECHANISMS OF INTERACTIONS}

Papers presented here either focused on transitional periods or reviewed archaeological data with a different angle of approach. Doing so, northern-southern Levantine connections are noticed, nuanced or redefined. We all agree that there are connections between all the regions of the Levant through time, although according to our domain of expertise, direction and modality of diffusion are understood differently. Several authors seem to agree on a complex and nonlinear web of diffusion of technological knowledge from north to south implying possible moving of specialized craftsmen (Ibáñez et al.; Borrell and Khalaily; Gabrieli) while others favour a rapid diffusion by pulses of several cultural elements spread as a package (Edwards). In any case the role played by the intermediate sites in areas where innovations will occur remains unclear. The direction from north to south is usually supported with an array of ${ }^{14} \mathrm{C}$ dates. Progressive local adaptation or appropriation of northern elements into southern assemblages is thoroughly examined (Borrell and Khalaily) following previous work (e.g., Barzilai 2010; Le Dosseur 2006). The identification of the specificities of southern traditions within northern influences for all categories of items is an urgent matter and the only way to catch some cultural elements originated from south that may have diffused to the north. A unidirectional network system from core to periphery (e.g., Cauvin 1994; Kozłowski and Aurenche 2005) is highly questionable (e.g., Rollefson and Gebel 2004 and discussions therein; Asouti 2006), but it must be said that few available data promote a south to north diffusion. It might be the case of the skull removal behaviour in primary contexts, which exists on a panregional scale during the PPNB but is much more emphasized in the south where it might originate (Bocquentin et al.). Later in EC contexts, roots of a common symbolic interaction sphere could also have been initiated in the Southern Levant (Milevski et al.).

Our capacity for identifying interactive processes is questioned by most of the articles in this issue. Are we taking into account the relevant criteria? Are type groups or architectural features significant enough to understand socio-cultural ties? Should we reduce the great history of the neolithization in the Near East as superimposed items on a map? Functional analyses (Vieugué et al.), technological evolutionary history (Borrell and Khalaily), architecture spatial concept (Andreou) or gestures and intentionality (Bocquentin et al.) do provide as well interesting indications of connection and disconnection. 
Diffusion and transmission are made through networks of variable size, according to a different timescale. They will depend on one side on the dynamic of the innovation centre, being itself dependant on the socioeconomic and environmental (in)stabilities. On the other side, the success of the diffusion will depend on the receptivity of further groups. Geographical proximity does not necessary mean wider flow of exchanges, as bounded borders did exist (Borrell and Molist 2014). Neither traditional networks do function for ever: breaks of cultural flow are documented (Bocquentin et al.; Borrell and Khalaily). Should we consider the reduction of cultural networks as a sign of stagnation or, on the contrary, as a dynamic process of adaptability, which aimed to maintain stable a social structure weaken by extrinsic elements? The necessity for approaching these issues as a coherent system becomes an obvious but challenging goal.

No doubt that an exchange system has existed on a supraregional scale. It might include items exchanges, craftsmen translation, marriage, and raw material trade. Neither movement of population, nor polycentric innovations resulting of local adaptation or of the reconfiguration of foreign influences should be excluded. The different nature of exchanges (products, raw materials, individuals, cultivars, technologies, ideas, symbols, etc.) must certainly had have different means, paths, and directions, as well as different rhythms of diffusion, whether or not following the models of Renfrew (1975) or others (e.g., Ibáñez et al.; Rollefson and Gebel 2004 and discussion therein; Milevski 2011: 17-33).

The "interaction sphere" model (Caldwell 1964) has been utilized by part of the contributions in this volume, adapted as a valuable tool to evaluate connections and disconnections in different aspects of the archaeological record within the Levant and beyond (Gómez Bach et al., Milevski et al.; Gabrieli). This model suggests a complex exchange networks through which specific goods or prestige items circulate, connecting distinct societies who exhibit diverse regional cultural traditions in their material culture. In a way, the model described by Caldwell would resemble to the definition of the koine by J. Cauvin (1994), which promotes shared symbolic ideologies. If the "interaction sphere" model is embraced by a number of Neolithicians, not without criticisms (e.g., Asouti 2006; Borrell and Molist 2014), yet the degree of interaction as well as the social context of these exchanges (tribal or intertribal) is still not well defined. This model has been interpreted differently in the past for the PPNB of the Levant as an intricate web of exchange based on social and economic complementarity between different tribal areas (Bar-Yosef and Belfer Cohen 1989; Bar-Yosef 2001). For later periods, N. Yoffee (1993) has utilized this model in order to explore the usefulness of the concept in the PN of Mesopotamia, using the data of the Hassuna, Samarra, and Halaf cultures.

Disentangling as much as we can this complex web of exchanges spheres, item by item, phase after phase, could help us to reconstruct part of the forces and mechanisms involved in the 'interaction sphere' model.

\section{PERSPECTIVES}

Meanwhile, all contributions put forward the difficulties they face trying to connect Southern and Northern Levant research: data heterogeneous in nature, quality and quantity, absence of a common vocabulary, irrelevant classifications for comparison, absence of ${ }^{14} \mathrm{C}$ landmarks, mismatched or misdefined chrono-cultural entities. Edwards argued for a new nomenclature in order to take into account the regional specificity of the development of the neolithization process across the Levant. It is a fact that Neolithic archaeology in the Levant uses the same terminology inherited from K. Kenyon (1960) for distant areas, displaying a vast array of cultural traditions and showing different or delayed historical dynamics (Rollefson and Gebel 2004). But which scale of cultural affinities should we take up as significant enough to draw borders? And should lithic traditions or pottery be always considered as more relevant than other criteria? Indeed, lithic or pottery assemblages are abundant materials, well preserved, various enough and fast changing providing us with a valuable tool for defining part of cultural dynamics. But other criteria as space anthropization, animal and plant exploitation, architectural techniques, burial practices, stone vessels, goods, figurines, etc. must also be integrated into a high resolution approach if we want to understand the reasons and meaning of the changes and the porosity of the borders. Pioneer research in this sense seems to succeed in identifying clear (despite unexpected) borders in PPNB contexts (Borrell and Molist 2014), which do not however follow previous territorial partitions (e.g., Kozłowski and Aurenche 2005).

An attempt was made for the $6^{\text {th }}$ millennium in the Southern Levant to adopt a multi-nomenclature reflecting the plurality of each micro-region. But it seems that this choice resulted in a certain confining in research and concealed pan-regional connections (Gómez Bach et al.; Milevski et al.). A regional scale composite nomenclature separating dates/area/culture might be a solution to clarify major ambiguous chrono-cultural entities. While the borders are clearer in Protohistoric periods, such as the LC and EBA, the ambiguity exists for instance in 
defining what is LC in each region of the Levant. EBA entities have been more evenly defined in both the Northern and Southern Levant, in spite of the fact that the pace of developments in each phase of this period is totally different in each region. For example, the reality of the EBA IV is totally different in the North and in the South, although both regions have almost the same nomenclature (Akkermans and Schwartz 2009: 181-287; but see Prag 2014 for instance). These difficulties in choosing a nomenclature become even more noticeable for the so-called 'transitional periods' (end of Pre-Pottery Neolithic, end of Pottery Neolithic) while lower cultural dynamics and consequently slower diffusion process result in a strong timing offset of regional processes. This is why cultural traits cannot be considered as chronological markers without dating, at the risk of generating circular reasoning as reminded by Edwards. Accurate dating of sites is a major issue in the future. Fine stratigraphic records and ${ }^{14} \mathrm{C}$ dates should be an absolute priority as far as preservation of sites permits it.

The question of radiocarbon dates was debated nearly ten years ago (Banning 2007) also in a thematic issue of Paléorient. Some specific problems on the radiocarbon calibration curve exist when dealing with certain periods of the late Prehistory (Manning 2007; Campbell 2007). Moreover, available ${ }^{14} \mathrm{C}$ dates for sites are not always pointing out to the beginning and the end of a period or to a specific technological or iconographic phenomenon. If we wish to know the dates for these phenomena, the best would be to concentrate on dating samples that we can reasonably associate with such events as the initial construction of buildings on site and the last use of a hearth before site abandonment (Banning 2007). Needless to say that incomplete ${ }^{14} \mathrm{C}$ sequences can result in a misunderstanding of phenomenon and on the direction of influences from north to south or vice versa (see for instance recent debates on Halaf/Wadi Rabah connections: Campbell 2007; Streit 2016). Ones should always keep in mind that our data are partial. Moreover, differences in preservation of sites emphasized this issue. Sites located in a Mediterranean ecosystem are far less well preserved than those situated in dryer ecosystems. It has a strong impact on research at different levels: the fine scale stratigraphic reading of Mediterranean sites is altered, the materialization of cultural diversity is shoddier and the role that those areas may have played in the historical processes is therefore abraded.

Still, the perspective of comprehensive analyses of synchronic or diachronic entities should be a priority in order to build comparable sets of information for the different entities and regions of the Levant in Prehistory and Protohistory. The investigation on connections' patterns in the Levant should iden- tify regional temporal facets and stages. Fine scale studies field by field are definitely needed. A comprehensive study of wellcontextualized materials is a valuable and essential source of perennial data. Usually, more powerful are the "magnifying glasses" of observation the more regional diversities are observed, which pertinently questions the spheres of interaction (e.g., Rollefson 2004; Hermansen 2004; Asouti 2006; papers in this volume). In the same way, apparent macro discontinuity might, in fact, conceal comparable conceptual ideas (e.g., Andreou). In prospect, collective discussions gathering specialists of all fields (tools, containers, foodstuffs, architecture, iconography, burial customs, radiocarbon data, environment, landscapes, etc.) on regional and supra-regional scales would permit to develop a systemic approach at a structural level (see also Gebel 2004). If the different elements playing a role in the connection/disconnection dynamic are roughly known, their interactions and diachronic evolution are far from being well understood. Convergences and discrepancies that could be thoroughly compared on a high resolution scale about a technological evolutionary process, environmental changes, economical shifts or ritual behaviours, would certainly shed some light on the meaning of innovation/stabilization, on the different scales of social interactions and on the various rhythms of adaptation.

The present discussion is a call for such a multi-disciplinary debate in order to push for common research platforms where we could study together different regional connections or disconnections in the Prehistory and Protohistory of the Levant, learning from the materials of other colleagues.

Fanny BOCQUENTIN CNRS, UMR 7041 ArScAn Ethnologie Préhistorique Maison Archéologie et Ethnologie 21 allée de l'Université 92023 Nanterre - FRANCE fanny.bocquentin@cnrs.fr

Miquel MOLIST
Universitat Autònoma de Barcelona
Departament de Prehistòria
08193 Bellaterra (Barcelona) - SPAIN
miquel.molist@uab.es

Ianir MILEVSKI

Israel Antiquities Authority Excavations, Surveys and Research Department POB 586-91004 Jerusalem - ISRAEL ianir@israntique.org.il 


\section{BIBLIOGRAPHY}

AKKERMANS P.M.M.G. and SCHWARTZ G.

2009 The Archaeology of Syria. From Complex Hunter-Gatherers to Early Urban Societies (ca. 16,000-300BC). New York: Cambridge University Press.

ASOUTI E.

2006 Beyond the Pre-Pottery Neolithic B interaction sphere. Journal of World Prehistory 20: 87-126.

BANNING E.B.

2007 Time and Tradition: Problems of Chronology in the $6^{\text {th }}-4^{\text {th }}$ millennia in the Levant and Greater Mesopotamia. Paléorient 33,1: 137-142.

BAR-YOSEF O.

$2001 \quad$ Lithic and the social geographic configurations identifying Neolithic tribes in the Levant. In: CANEVA I., LEMORINI C., ZampetTi D. and BIAGI P. (eds.), Beyond Tools. Redefining PPN Lithic Assemblages of the Levant: 437-448. Berlin: ex Oriente.

BAR-YOSEF O. and BELFER-COHEN A.

1989 The Levantine "PPNB"' interaction sphere. In: HERSHKOVITZ I. (ed.), People and Culture in Change: Proceedings of the Second symposium on Upper Paleolithic, Mesolithic and Neolithic Populations of Europe and the Mediterranean Basin: 59-72. Oxford (BAR Int. Ser. 508,1).

\section{BARZILAI O.}

2010 Social Complexity in the Southern Levantine PPNB as Reflected through Lithic Studies. Oxford (BAR Int. Ser. 2180).

BORRELL F. and MOLIST M.

2014 Social interaction at the end of the Pre-Pottery Neolithic B: An inter-site analysis in the Euphrates valley. Cambridge Archaeological Journal 24,2: 215-232.

CALDWELl J.R.

1964 Interaction Spheres in Prehistory. In: CALDWELL J.R. and HALL R.L. (eds.), Hopewellian Studies: 134-143. Springfield: Illinois State Museum (Illinois State Museum Scientific Papers 12).

CAMPBELL S

2007 Rethinking Halaf Chronologies. Paléorient 33,1: 103-136

CAUVIN J.

$1994 \quad$ Naissance des divinités, naissance de l'agriculture. Paris: Éditions CNRS.

EDWARDS P.C. and SAYEJ G.

2007 Resolving contradictions: The PPNA - PPNB transition in the Southern Levant. In: ASTRUC L., BINDER D. et BRIOIS F. (éd.), Systèmes techniques et communautés du Néolithique précéramique au Proche-Orient/ Technical Systems and Near Eastern PPN communities: 117-125. Antibes: APDCA.

GEBEL H

2004 There was no center: The polycentric evolution of the Near Eastern Neolithic. Neo-Lithics 1/04: 28-32.

HERMANSEN B.D.

2004 Supra-Regional Concepts from a local perspective. Neo-Lithics 1/04: 34-38.
KENYON K.M.

1960 Archaeology of the Holy Land. New York: Praeger.

KOZŁOWSKI S.K. and AURENCHE O.

2005 Territories, Boundaries and Cultures in the Neolithic Near East. Oxford (BAR Int. Ser. 1362)

LE DOSSEUR G

2006 La néolithisation au Levant Sud à travers l'exploitation des matières osseuses. Études techno-économiques de onze séries d'industries osseuses du Natoufien au PPNB récent. Thèse de doctorat non publiée. Université de Paris 1.

LOVELL J.L. and ROWAN Y.M.

2011 Culture, Chronology and the Chalcolithic. Theory and Transition. Oxford: Oxbow books (Levant Supplementary Series 9).

MANNING S.W

2007 Beyond Dates to Chronology: Rethinking the NeolithicChalcolithic Levant. Paléorient 33,1: 5-10.

MILEVSKI I.

2011 Early Bronze Age Goods Exchange in the Southern Levant. A Marxist Perspective. London: Equinox.

POLANYI K.

1957 The Economy as Instituted Process. In: POLANYI K., ARENSBERG C.M. and PEARson H.W. (eds.), Trade and Market in the Early Empires. Economies in History and Theory: 243270. Chicago: The Free Press.

PRAG K.

2014 The Southern Levant during the Intermediate Bronze Age. In: STEINER M.L. and KILlEBREW A.E. (eds.), The Oxford Handbook of the Archaeology of the Levant: c. 8000-332 BCE: 388-400. Oxford: Oxford University Press.

RENFREW C.

1975 Trade as Action at a Distance: Questions of Integration and Communication. In: SABLOFF J.A. and LAMBERG KARLOVSKI C.C. (eds.), Ancient Civilization and Trade: 3-60. Albuquerque: University of New Mexico Press.

ROLLEFSON G.

2004 A reconsideration of the PPN koiné: cultural diversity and centralities. Neo-Lithics 1/04: 46-48.

ROLLEFSON G. and GEBEL H.G.K.

2004 Towards new frameworks: Supra-regional concepts in Near Eastern Neolithization. Neo-Lithics 1/04: 21-22.

STREIT K.

2016 The Near East before Borders: Cultural Interaction between Mesopotamia, the Levant and Lower Egypt at 5880-5200 BC. Unpublished PhD Thesis. The Hebrew University of Jerusalem.

YOFFE N.

1993 Mesopotamian Interaction Spheres. In: YOFFE N. and CLARK D. (eds.), Early Stages in the Evolution of Mesopotamian Civilization (Soviet Excavations in Northern Iraq): 257-270. Tucson: The University of Arizona Press. 